\title{
PraCTICE
}

Public Health

\section{Release of the statement on influenza for the 2007-2008 season from the National Advisory Committee on Immunization}

A $s$ the influenza season winds to a close in the southern hemisphere, public health programs in Canada are preparing to launch vaccination campaigns to protect against an infection that accounts for about 4000 excess deaths each winter. ${ }^{1}$ The number of reported cases of influenza is 3 times greater than average in several Australian states as of September 2007; however, the influenza strains in circulation are similar to those that were seen in the 2006/07 season in the northern hemisphere, and they match well with the strains covered by the seasonal vaccine. ${ }^{2}$ In Canada, the recommendations for influenza prevention are revised yearly by the National Advisory Committee on Immunization in response to updated surveillance and laboratory and clinical evidence. In this Public Health column, 2 important changes in the recommendations for the 2007/08 season are highlighted (Box I, Box 2). ${ }^{3}$ Vaccination against influenza is now recommended for all pregnant woman, and the recommended vaccination schedule for children aged 9 years or younger has been changed. The committee has also reiterated the importance of vaccination as the primary means of preventing influenza.

It is recognized that pregnant women with concurrent conditions, such as cardiac or pulmonary disease, are at high risk for complicated influenza. ${ }^{4}$ However, the rate of immunization among pregnant women is low. ${ }^{5}$ Recently, 2 Canadian studies have shown that healthy pregnant women with influenza are more likely than nonpregnant women with influenza to have medical visits and to be admitted to hospital. Theoretically, expanding immunization programs to include all pregnant women may increase immunization uptake among pregnant women at high risk for complicated influenza. The provision of

\section{Box 1: Recommended recipients of influenza vaccine}

People at high risk for influenza-related complications

- Adults and children with select chronic health conditions, if the condition is significant enough to require regular follow-up or hospital care, including:

- cardiac or pulmonary conditions (e.g., bronchopulmonary dysplasia, cystic fibrosis, asthma)

diabetes mellitus, other metabolic diseases

cancer, immunodeficiency or immune suppression (due to underlying disease or therapy)

renal disease

anemia or hemoglobinopathy

conditions that compromise the management of respiratory secretions and that are associated with an increased risk of aspiration

children and adolescents with conditions that have been treated for long periods with acetylsalicylic acid

- People of any age who are residents of nursing homes or other long-term care facilities

- People aged 65 years or greater

- Healthy children aged 6-23 months

- Pregnant women, including those with select high-risk conditions and healthy pregnant women

People capable of transmitting influenza to those at high risk of influenza-related complications

- Health care and other care providers in facilities and community settings

- Household contacts (adults and children) of people at high risk for influenza complications, whether or not the people at high risk have been immunized. Includes household contacts of infants aged 6 months or younger (who are at high risk of complications from influenza but for whom there is no effective vaccine available), children aged 6-23 months and pregnant women

- People who provide care to children under 24 months of age, whether in or out of the home

Others

- People who provide essential community services

- People who provide services within closed or relatively closed settings to persons at high risk (e.g., crew on ships)

- People responsible for culling poultry infected with avian influenza

- Healthy people aged 2-64 years, who should be encouraged to receive the vaccine even if they are not in one of the above priority groups

Source: National Advisory Committee on Immunization. Statement on influenza vaccination for the 2007-2008 season. Public Health Agency of Canada (2007). Reproduced with permission of the Minister of Public Works and Government Services Canada, 2007. 
Box 2: Recommended influenza vaccination schedule for children aged 6 months to 9 years

- Infants 6-35 months: $0.25 \mathrm{~mL}$ per vaccination

- Children 3-8 years: $0.5 \mathrm{~mL}$ per vaccination

First year of immunization

- 2 doses, 4 weeks apart

Second year of immunization

- If the child received 2 doses in prior year, only 1 dose is needed

- If the child received 1 dose in prior year, 2 doses 4 weeks apart are needed

Third year of immunization

- If the child received 2 doses in either of the 2 preceding years, only 1 dose is needed

- If the child received only 1 dose in each of 2 preceding years, only 1 dose is needed

a universal program for influenza vaccination in Ontario has been associated with an increase in the rate of vaccination coverage among people with chronic conditions to $56 \%$ from $38 \%$ between 1996 and 200I. In all other provinces combined, the immunization rate increased to $38 \%$ from $27 \%$ between 1996 and 200I. ${ }^{8}$ A strategic approach to capturing this changing population will need to be considered by primary care practitioners, specialists providing obstetric care and public health. ${ }^{5}$

The second major change in the recommendations involves children under 9 years of age who received only I dose of vaccine in the previous year. A single dose of vaccine in the first year of vaccination does not appear to provide protection. ${ }^{9-11}$ The committee now recommends a 2-dose schedule for children under 9 years of age if they received only I dose in the previous year (Box 2). This recommendation is based on evidence of reduced protection against influenza among children who received only I dose in their first and second years of vaccination. This recommendation parallels those made by the American Academy of Pediatrics and the Advisory Committee on Immunization in the United States. ${ }^{3,12}$
Other major recommendations from the National Advisory Committee on Immunization have not changed. They strongly recommend immunization for people who are considered at high risk for complications from influenza (Box I). Vaccination of people who may transmit influenza to those at high risk, such as caregivers or household members, continues to be a key recommendation to prevent influenza-related morbidity and mortality (Box I). The committee also continues to encourage vaccination for personal protection against influenza (i.e., direct benefit) for people aged 24 months-64 years who are not pregnant, are healthy and who will not be in close contact with people at high risk. The potential indirect benefit of vaccination among healthy people for the prevention of the secondary spread of influenza continues to be a focus of research and topic of discussion in the public health community. ${ }^{13}$

As in 2006/07, the National Advisory Committee on Immunization recommends that only neuraminidase inhibitors, not amantadine, be used for antiviral prophylaxis. Antiviral prophylaxis is most likely to be used in shortor long-term care institutions, including residential settings, where influenza outbreaks occur, or for people who are at high risk but cannot be vaccinated or who may have an inadequate immune response (e.g., people who are immune compromised). This recommendation was made in late 2006 when antiviralsusceptibility testing revealed that most isolates were resistant to amantadine and that these drug-resistant viruses were present throughout Canada. Although the prevalence of resistant strains in 2006/07 was lower than in the previous season, the continued presence of amantadine-resistant strains of influenza means that amantadine cannot be used to provide protection for vulnerable people. Randomized controlled trials of neuraminidase inhibitors as seasonal prophylaxis or as postexposure prophylaxis indicate these drugs are $56 \%-90 \%$ effective in preventing laboratory-confirmed influenza among healthy people. ${ }^{14}$ The National
Advisory Committee on Immunization notes that antiviral prophylaxis should be considered only as an adjunct to immunization for influenza prevention.

\section{Joanne M. Langley MD}

Division of Infectious Diseases

Department of Pediatrics

Dalhousie University

Halifax, NS

Competing interests: None declared.

\section{REFERENCES}

I. Schanzer DL, Tam TW, Langley JM, et al. Influenzaattributable deaths, Canada I990-I999. Epidemio Infect 2007;Feb I9;I-8. [Epub ahead of print].

2. Department of Health and Ageing. Australian influenza report: report 9. Australia: The Government; 2007. Available: www.foodsecretariat.health.gov.au /internet/wcms/publishing.nsf/eriffa33Ib366c54ca 2569210006982f/cda-surveil-ozflu-flucurr.htm (accessed 2007 Sept I9).

3. Public Health Agency of Canada. Statement on influenza vaccination for the 2007-2008 season: an Advisory Committee Statement. Can Commun Dis Rep 2007;33:1-38. Available: www.phac-aspc.gc .ca/publicat/ccdr-rmtc/o7vol33/acs-07/index_e.html (accessed 2007 Sept I9).

4. Public Health Agency of Canada. Statement on influenza vaccination for the 2006-2007 season: an Advisory Committee Statement. Can Commun Dis Rep 2006;32:I-27. Available: www.phac-aspc.gc.ca /publicat/ccdr-rmtc/o6vol32/acs-07/index.html (accessed 2007 Sept I9).

5. McNeil SA, Dodds L, Allen VM, et al. Influenza vaccine programs and pregnancy: new Canadian evidence for immunization. J Obstet Gynaecol Can 2007;29:674-6.

6. Dodds L, McNeil SA, Fell DB, et al. Impact of in fluenza exposure on rates of hospital admissions and physician visits because of respiratory illness among pregnant women. $C M A J$ 2007;176:463-8.

7. Schanzer DL, Langley JM, Tam TW. Influenza-attributed hospitalization rates among pregnant women in Canada 1994-2000. J Obstet Gynaecol Can 2007;29:622-9.

8. Kwong JC, Sambell C, Johansen H, et al. The effect of universal influenza immunization on vaccination rates in Ontario. Health Rep 2006;17:31-40.

9. Allison MA, Daley MF, Crane LA, et al. Influenza vaccine effectiveness in healthy 6 - to $2 \mathrm{I}$-month-old children during the 2003-2004 season. J Pediatr 2006;149:755-62.

Io. Ritzwoller DP, Bridges $\mathrm{CB}$, Shetterly $\mathrm{S}$, et al. Effectiveness of the 2003-2004 influenza vaccine among children 6 months to 8 years of age, with I v. 2 doses. Pediatrics 2005;116:153-9.

II. Shuler CM, Iwamoto M, Bridges CB, et al. Vaccine effectiveness against medically attended, laboratoryconfirmed influenza among children aged 6 to 59 months, 2003-2004. Pediatrics 2007;IIg:e587-95.

I2. American Academy of Pediatrics Committee on Infectious Diseases. Prevention of influenza: recommendations for influenza immunization of children, 2006-2007. Pediatrics 2007;II9:846-5I.

I3. Schwartz B, Hinman A, Abramson J, et al. Universal influenza vaccination in the United States: Are we ready? Report of a meeting. J Infect Dis 2006; I94(Suppl 2):Si47-54.

I4. Allen UD, Aoki FY, Stiver HG. The use of antivira drugs for influenza: recommended guidelines for practitioners. Can J Infect Dis Med Microbiol 2006; 17:273-84. 